\title{
Methods for Increasing the Rating of Overhead Lines
}

\author{
I. Albizu, A. J. Mazón, I. Zamora
}

\begin{abstract}
At the present time, there is great pressure to increase the power flow in existing right of ways using existing infrastructure as far as possible. In this paper, the diverse options for increasing the rating of overhead lines are presented and analyzed. By means of a comparative study, their advantages and drawbacks are highlighted. In addition, the factors that determine the choice of the method are analyzed.
\end{abstract}

Index Terms - overhead line, ampacity, thermal rating, upgrading, uprating.

\section{INTRODUCTION}

$\mathrm{T}$ $\neg$ HE power flow in electrical lines has increased considerably in recent times. There are several reasons for this increase. Firstly, the technological growth and the increase of the quality-of-life have led to a growing demand for electrical power. Secondly, the deregulation of the electrical generation and the consequent changes on generation connected to the transmission system has caused major changes in the power flows across transmission lines. In addition, embedded generation connected directly to the distribution network impacts on the power flow across the distribution system.

As a result of the increased power flow, some lines can be close to its ampacity limit. As defined in [1], the "ampacity" or "thermal rating" is "that current which will meet the design, security and safety criteria of a particular line on which the conductor is used”. An excessive conductor temperature may give rise to an excessive elongation of the conductor with consequent dangerous reduction of the clearances to ground. In addition it also could produce annealing and high temperature creep of the conductor and a decrease of the capability of compression joints. All these effects caused by an excessive current could put public safety at risk.

In order to cope with this problem new lines could be installed. However, the high population density, the intensive use of land and the increasing rejection of new electrical installations determine that a small amount of space is available to be dedicated to electrical lines. As a consequence, legislations ruling the construction of overhead lines establish a great number of previous steps such as permissions, public presentation of the project, rights for the presentation of allegations, etc. Hence, the elapsed time since the need for the installation of a line arises until the line is finally commissioned can easily be a decade or longer. Therefore, there is great pressure to increase the power flow in existing right of ways using existing infrastructure as far as possible.

Traditionally, the upgrading of the line has been used in order to increase the line rating. The upgrading involves increasing the line voltage or the number of conductors. The main drawback of these methods is the need to strengthen the towers.

For this reason, methods without the need to strengthen the towers that allow to increase line power flow securely and safely, close to its ampacity limit, have been developed. Among these methods, probabilistic methods and real time monitoring can be found. Another option is to increase the ampacity of the line by conductor replacement. The new conductor needs to have better properties, such as lower sagtemperature relation.

In this paper, the diverse options for increasing the rating of overhead lines are presented and analyzed. By means of a comparative study, their advantages and drawbacks are highlighted.

\section{UPGRADING OF OVERHEAD LINES}

Upgrading strategies of overhead lines are divided into two types of methods for increasing the rating:

- Increase of ampacity

- Increase of voltage

The rating increase by the increase of ampacity does not affect the line voltage. The value that is increased is the line maximum current, without decreasing safety. Traditionally, the increase in current has been achieved increasing the conductor section by the increase of the number of conductors per phase.

The rating increase by the increase of voltage is based on the line rated voltage increase. This method allows a considerable rating increase.

\section{A. Increase of Conductor Section}

The increase of conductor section reduces the electrical resistance. As a consequence, for a certain current value, the heat dissipated due to Joule effect is reduced. In other words, in order to dissipate the same amount of heat, it is needed a

I. Albizu, A. J. Mazón and I. Zamora are with the Department of Electrical Engineering, The University of the Basque Country, Bilbao (e-mail: 
higher current value. Hence, the ampacity is increased.

In order to increase the conductor section it can be replaced by another of larger section. However, the usual solution is to increase the number of conductors per phase.

Examples of the increase of the conductor section are described in $[2,3]$. These examples correspond to different countries such as Germany [2] and Spain [3] and are shown in Table I.

TABLE I

CASES OF INCREASE OF CONDUCTOR SECTION

\begin{tabular}{|c||c||c|c||}
\hline Case & $\begin{array}{c}\text { Voltage } \\
(\mathrm{kV})\end{array}$ & $\begin{array}{c}\text { Original } \\
\text { Conductor }\end{array}$ & New Conductor \\
\hline S1 [2] & 380 & 2 ACSR 560/50 & 4 ACSR 265/35 \\
\hline S2 [3] & 132 & 1 ACSR Hen & 2 ACSR Hawk \\
\hline
\end{tabular}

In Table II, the rating increase and the saving with respect to the investment in a new line are shown.

TABLE II

RATING INCREASE AND SAVING WITH RESPECT TO A NEW LINE

\begin{tabular}{|c||c||c||}
\hline Case & $\begin{array}{c}\text { Rating } \\
\text { Increase (\%) }\end{array}$ & $\begin{array}{c}\text { Saving with respect } \\
\text { to a New Line (\%) }\end{array}$ \\
\hline S1 [2] & 31 & 53 \\
\hline S2 [3] & 100 & - \\
\hline
\end{tabular}

The conductor replacement results in some changes in the insulators, the towers and the foundations. The insulators have to be adapted to the new conductor configuration. The increase in section results in an weight increase. For this reason, the mechanical requirement of the towers is increased and it is usual the need for tower and foundation reinforcement.

\section{1) Insulators}

When the number of conductors is increased, the bundle swinging increased and the existing horizontal distances may not be enough to guarantee the safety. If it is necessary to respect the right-of-way and it is not possible to increase horizontal distances, a system that limits the lateral swinging is used. This is the case of example S1, where an asymmetric V-type insulator is installed in order to limit the lateral swinging of the new quad bundle conductor.

2) Tower Reinforcement

The increase of the mechanical requirement of the towers forces to the analysis of their capacity. In case that the capacity of the tower is exceeded it has to be reinforced. If the reinforcement is not enough, the tower is replaced. In the case S2, the lattice towers need to be reinforced. The bracing of the lower diaphragms is carried out to prevent the steel members from buckling. In the suspension towers, double angle members are installed in the legs of the lower panel. In the angle and tension towers, double angle members are installed for complete tower legs and some diagonal members are replaced in the upper part of the body. In a similar way, in the case S1, the lattice towers are reinforced. The compression forces increase a $13 \%$ and for this reason new angle profiles are installed for complete tower legs.

\section{3) Foundation Reinforcement}

The foundation requires also to be checked due to the increase of forces. Both in case S1 and S2, the foundations need to be reinforced. In the case S2 a calculation method is used to estimate the reinforcement need. In the case S1, the foundations are physically tested to achieve better results.

\section{B. Increase of Line Voltage}

If the current value of a line is close to the ampacity limit, the increase of line voltage reduces the current value for the same transmitted power. Hence, the margin with respect to the ampacity limit is increased.

However, the cost of the voltage increase is high. The electrical isolation has to be increased and the towers and foundations need to be reinforced. Besides the changes in the line, the substation equipment also has to be adapted to the higher voltage. For this reason, the increase of rating by the increase of voltage has to be analyzed exhaustively in order to determine its feasibility [4].

Examples of application of increase of line voltage are described in $[2,5,6]$. These examples correspond to different countries such as USA [5,6] and Germany [2] and are shown in Table III.

When the line voltage is increased, it is usual to increase the conductor section as well, in order to achieve a larger increase of rating. This can be observed in the cases shown in Table III.

TABLE III

CASES OF INCREASE OF LINE VOLTAGE

\begin{tabular}{|c|c|c|c|c|}
\hline Case & $\begin{array}{c}\text { Original } \\
\text { Voltage }(\mathrm{kV})\end{array}$ & $\begin{array}{c}\text { New Voltage } \\
(k V)\end{array}$ & Original Conductor & New Conductor \\
\hline V1 [5] & 115 & 230 & $\begin{array}{c}1 \text { ACSR } \\
266,8 \text { kcmil 26/7 }\end{array}$ & $\begin{array}{c}1 \text { ACSR } \\
795 \mathrm{kcmil} 24 / 7\end{array}$ \\
\hline V2 [6] & 115 & 230 & $\begin{array}{c}1 \text { ACSR } \\
954 \mathrm{kcmil} \mathrm{54/7}\end{array}$ & The same \\
\hline V3 [6] & 230 & 345 & $\begin{array}{c}1 \text { ACSR } \\
1272 \mathrm{kcmil} \mathrm{45/7}\end{array}$ & $\begin{array}{c}2 \text { ACSR } \\
1272 \mathrm{kcmil} 45 / 7\end{array}$ \\
\hline V4 [6] & 230 & 345 & $\begin{array}{c}1 \text { ACSR } \\
1272 \mathrm{kcmil} \mathrm{45/7}\end{array}$ & $\begin{array}{c}2 \text { ACSR } \\
1272 \mathrm{kcmil} 45 / 7\end{array}$ \\
\hline V5 [6] & 230 & 500 & - & $\begin{array}{c}3 \text { ACSR/TW } \\
1565 \mathrm{kcmil} \mathrm{36/7}\end{array}$ \\
\hline V6 [2] & 220 & 380 & 2 ACSR $240 / 40$ & 3 ACSR $340 / 30$ \\
\hline V7 [2] & 220 & 380 & 2 ACSR $240 / 40$ & 3 ACSR $340 / 30$ \\
\hline
\end{tabular}

In Table IV, the rating increase and the saving with respect to the investment in a new line are shown.

TABLE IV

RATING INCREASE AND SAVING WITH RESPECT TO A NEW LINE

\begin{tabular}{|c||c||c|}
\hline Case & $\begin{array}{c}\text { Rating } \\
\text { Increase (\%) }\end{array}$ & $\begin{array}{c}\text { Saving with respect } \\
\text { to a New Line (\%) }\end{array}$ \\
\hline V2 [6] & - & 40 \\
\hline V3 [6] & - & 45 \\
\hline V4 [6] & - & 45 \\
\hline V5 [6] & - & 50 \\
\hline V6 [2] & 217 & 32 \\
\hline V7 [2] & 200 & 42 \\
\hline
\end{tabular}




\section{1) Insulators}

Due to the increase of line voltage, the electrical isolation has to be increased. The use of longer insulators reduce the vertical distance between conductors and ground. In order to compensate this effect, the conductor connection point can be raised (cases V1, V2, V5), or the conductor tension can be increased. In order to raise the conductor connection point some changes in the structure are needed. The increase of conductor tension increases the forces in the tower and the foundations.

In addition, due to the increases in voltage and isolator length, the distances between phases and between phases and tower may be not enough to guarantee the safety. For this reason, in cases V2-V6, I-strut or V-string isolators are used in order to limit conductor movement.

\section{2) Tower Reinforcement}

The increase of the mechanical requirement of the towers forces to the analysis of their capacity. In case that the capacity of the tower is exceeded it has to be reinforced. If the reinforcement is not enough, the tower is replaced. In case V1, the top of the wooden tower structure, the X-braces and the tower base have been reinforced. In case V2, some suspension towers have been replaced by new ones and other ones have been replaced by tension towers. In addition, more tension towers have been installed to reinforce the line. In case V4, the number of legs of the lattice tower has been increased to six legs. Besides, some angle and tension towers have been replaced. In case V5, the towers also have been reinforced and some angle and tension towers have been replaced as well.

\section{3) Foundation Reinforcement}

The foundation requires also to be checked due to the increase of forces. In case V5 most of the foundation have been replaced by new ones. In case V6, the foundations have been reinforced.

\section{4) Electrical Field}

Another inconvenience of the voltage increase is related to the increase of electrical field and the risk of corona effect. The electrical field and corona noise values must comply with the existing regulations. The increase of the number of conductors of the conductor bundle helps to achieve this objective.

\section{MAXIMIZING LINE CURRENT}

In order to meet the design, security and safety criteria, the line current should be below the ampacity limit. The ampacity is a certain current that will result in the maximum allowable conductor temperature being reached. As defined in [1], the "maximum allowable conductor temperature" is "the highest conductor temperature at which an overhead power line can be safely operated". This limit is usually caused by clearance limits and not by annealing. The temperature limit due to clearance limit is known as templating temperature. Once the maximum allowable conductor temperature is determined, the current that will result in this temperature value will depend on weather conditions such as wind speed and direction, ambient temperature and solar radiation. Therefore, the ampacity is not a constant value as it depends on weather conditions.

Traditionally, the ampacity or thermal rating is calculated using deterministic assumptions of high ambient temperature, full solar radiation and a low wind speed. This condition is defined as the worst weather case. However, since this weather condition occurs only rarely, the line is capable of carrying a higher current nearly all of the time. In other words, when the line current equals the static thermal rating, the line temperature will be below the maximum allowable temperature.

For this reason, methods to increase the line current above the static thermal rating but below the actual ampacity have been developed. Some methods are based on statistical studies of weather data and load profiles in order to evaluate the probability of exceeding the ampacity value. Other methods calculate the real time ampacity by means of real time measurement of actual line temperature, tension or sag.

\section{A. Deterministic Method}

Taking into account the maximum allowable conductor temperature, the deterministic method calculates the line rating making assumptions of the wind direction, wind speed, ambient temperature and solar radiation. The ambient conditions to be used were determined in the sixties or seventies based on what was considered conservative at that time. No risk analysis was carried out.

The calculations usually follow the CIGRE Standard method [7] or the closely related IEEE Standard [8]. Ratings are calculated using deterministic assumptions of full solar radiation, high ambient temperature and low wind speed. Most utilities assume wind speeds of $0.5-0.6 \mathrm{~m} / \mathrm{s}$.

Some utilities, have recently increased the wind speed assumption to $0.9-1.2 \mathrm{~m} / \mathrm{s}$ in order to increase the rating. This is often done without assessing the associated risk and as a consequence the temperature can go above the maximum allowable conductor temperature for short periods of time. Hence, annealing may occur on the line conductors and security clearance may be exceeded.

\section{B. Probabilistic Method}

Taking into account the actual weather conditions prevalent in the geographical area of the line, probabilistic methods determine, for a given current value, either the amount of time the maximum allowable conductor temperature will be exceeded or the risk of an unsafe condition arising. Some of these methods are described in [9].

Examples of application of probabilistic methods are shown in [10-12]. These examples correspond to different countries such as United Kingdom [10], USA [11], and Italy [12]. Results show that the probabilistic thermal rating is higher than the static thermal rating. Furthermore, the risk taken is controlled.

The methods based on the amount of time the maximum temperature is exceeded determine the distribution of the ampacity, taking into account the distribution of the weather conditions during a period of time and the value of the 
maximum allowable conductor temperature. The percentage of acceptable exceedence is defined and the probabilistic thermal rating obtained. A comprehensive example of this method is shown in [10]. In [11] this method has been applied for the determination of the probabilistic thermal rating for high voltage transmission lines. Choosing an exceedence of $1 \%$ and changing the wind assumptions, an increase of around $15 \%$ over the deterministic rate has been obtained.

The methods based on the risk of an unsafe condition calculates the probability of risk for a given current value. The current value is changed until the probability value obtained equals the chosen value. In [12] a risk of $3.5 \cdot 10^{-5}$ is adopted in order to obtain the probabilistic thermal rating.

\section{Real Time Monitoring}

Real time monitoring allows line operation close to the ampacity limit [13]. The use of real time monitoring can increase the thermal rating on an average of $10 \%$.

Methods based on weather measurements [14] or conductor temperature monitoring $[15,16]$ have been used. However, due to the uncertainties of these methods, modern methods are based on either tension $[17,18]$ or sag [19] measurements.

Examples that correspond to different countries, such as Spain [14], USA [15,17-19], Japan [16], New Zealand [17,18] and Denmark [18] are shown.

1) Weather Measurement

This method uses weather and current measurements to calculate the conductor temperature. This temperature is used to determine the conductor sag value or it is compared with the maximum allowable temperature.

The weather stations monitor the weather at a particular point. But the wind speed varies along the line, depending on the terrain and the sheltering objects. Hence, this methods give errors in sections remote from the weather station.

Furthermore, when the wind speed is slow (critical condition), wind speed and direction measurements are inaccurate. The best results are obtained from ultrasonic anemometers.

Another source of error is related to the uncertainties in the sag/temperature relationship.

\section{2) Conductor Temperature Measurement}

Conductor temperature measurements are carried out by clamp-on sensors that transmit the data via radio. If the wind condition change along the line, the temperature in each section is different. Hence, the temperature should be measured in multiple locations in order to determine an average temperature.

Anyway, as it has been mentioned, there is a source of error related to the uncertainties in the sag/temperature relationship.

\section{3) Tension Measurement}

The tension is usually measured using a load cell in the strain assembly. The data are transmitted by cable or radio. The load cell is at ground potential.

As there is a close relation between tension and sag, the tension measurement is a good indicator of the actual clearance. For this reason it is widely used by many utilities.

\section{4) Sag Measurement}

The objective of the real time monitoring is to maintain the line above the security clearance. If it is possible to measure the sag directly, the errors associated to simplified assumptions are removed.

A method of conductor position measurement has been proposed recently based on differential GPS (DGPS) technology [19]. It measures conductor position within $17 \mathrm{~cm}$ with $70 \%$ confidence level.

\section{INCREASE OF CONDUCTOR TEMPLATING TEMPERATURE}

The simplest way of increasing the ampacity of overhead lines is to increase the conductor templating temperature, that is to say, the maximum temperature related to the clearance to ground or crossings. This increase takes into account the capability of the conductor and its fittings to accommodate the higher temperature.

In order to increase the clearance to ground, the height of the line can be increased with some minor physical modifications [20]. The techniques to increase the height of the line include re-tensioning the conductors or replacing the insulator strings. Another possibility is to increase tower height but this is an expensive option.

As an example, in South Africa a $400 \mathrm{kV}$ line of $50{ }^{\circ} \mathrm{C}$ have been increased to $85{ }^{\circ} \mathrm{C}$ with a rating increase of $60 \%$ [20]. The cost was $5 \%$ of the investment in new line. In the UK, ACSR lines of $50{ }^{\circ} \mathrm{C}$ have been increased to $75{ }^{\circ} \mathrm{C}$ with a rating increase of nearly $25 \%$ [21].

\section{RePlacement By LOW SAg CONDUCTOR}

Replacing the existing conductor by high-temperature lowsag conductors a considerable uprating is obtained without the need for strengthening the supports. With these conductors, the sag increases more slowly when the conductor temperature increases. Hence, for the same sag limit, they allow higher conductor templating temperature. The higher templating temperature allows a higher thermal rating.

There are several types of conductors available (G(Z)TACSR, ACSS(/TW), (Z)TACIR, etc). Examples of uprating with G(Z)TACSR [22-24], ZTACIR [22] and ACSS/TW [25] show the validity of this method.

In UK, the replacement by GZTACSR resulted in an increase of $130 \%$ in a $400 \mathrm{kV}$ line [23]. In Spain, the replacement by GTACSR results in an increase of $70 \%$ in a $132 \mathrm{kV}$ line [24]. In USA, the replacement by ACSS/TW could result in an increase of $70 \%$ in a $138 \mathrm{kV}$ line [25].

\section{CHOOSING BETWEEN THE DIFFERENT OPTIONS}

Choosing an appropriate method for uprating is a complicated process and the optimum choice varies from project to project [26]. Several factors have to be taken into account in order to choose the appropriate method. The condition of the existing assets, the characteristic of the rating constrain, the budgetary and time constraints and the availability of outages are factors that determine the method. 
If the existing assets are due for refurbishment within a short time, the upgrading of the line or the conductor replacement could be a good choice for the uprating. In the case of new assets, these options result in early asset write-off costs. In this case, real time monitoring or the increase of conductor templating temperature could be used as an alternative at the expense of a smaller uprating.

With respect to the size of the uprating, the methods differ considerably. The increase of voltage level is the method that achieves the highest rating increase. The increase of the conductor section or the replacement by low sag conductors achieve considerable increases as well. The increase of conductor templating temperature is not always possible and the increase obtained is more modest. Finally, the real time monitoring or the probabilistic methods are the methods that give the lowest uprating. Furthermore, the dynamic methods depend on the weather conditions and the enhancements cannot be guaranteed at any specific time.

The changes required for the uprating are related to the cost, the time and the outages needed. The increase of voltage level is the method that the most changes requires in the line. Hence, it is the most expensive solution and it takes long. The increase of the conductor section requires many changes in the line as well. The increase of conductor templating temperature requires minor modifications. The replacement by low sag conductors involves the replacement of the conductors but it has the advantage that no modification of the towers is needed. Finally, the real time monitoring and the probabilistic methods do not require modification in the line. However the real time monitoring needs monitoring equipment with its associated communications equipment and sometimes requires outages to install.

\section{CONCLUSIONS}

Options for the increase of the rating of overhead lines have been presented. The upgrading of overhead lines by the increase of conductor section or line voltage has been described. Methods to maximize the current values of the existing lines taking into account weather conditions have been analyzed as well. Finally, methods of uprating the lines have been presented. One method is based on the increase of the conductor templating temperature. Another uprating method is based on the conductor replacement by low-sag conductors.

In addition, the factors that determine the choice of the appropriate method have been analyzed. Many factors have to be taken into account in order to choose the appropriate method and the optimum choice varies from case to case.

\section{REFERENCES}

[1] "Conductors for the Uprating of Overhead Lines", CIGRÉ V2-12 Brochure (Ref. No. 244), 2004.

[2] F. Kiessling, D. Hussels, C. Juerdens, J. Ruhnau, "Upgrading highvoltage lines to increase their capacity and mitigate environmental impacts”, CIGRE Session, 22-208, Paris-France, 1998.
[3] D. Sanchez, C. Alonso, "Increase in transmission capacity in highvoltage power lines on the Levante (Eastern Spain) coastal path", CIGRÉ Session, V2-206, Paris-France, 2004.

[4] D.F. Shankle, "Incremental voltage uprating of transmission lines", IEEE Transactions on Power Apparatus and Systems, Vol.PAS-90, No. 4, pp. 1791-95, 1971.

[5] M. Broschat, "Transmission-line uprating $115 \mathrm{kV}$ to $230 \mathrm{kV}$ - Report on operating performance”, IEEE Transactions on Power Apparatus and Systems, Vol. PAS-91, No. 2, pp. 545-48, 1972.

[6] J.G. Hanson, "Upgrading transmission lines", IEEE PES T\&D Conference, pp. 824-27, Dallas-USA, 1991.

[7] “Thermal behaviour of overhead conductors”, CIGRÉ 22-12 Brochure (Ref. No. 207), 2002.

[8] IEEE Std 738-1993, "IEEE Standard for Calculating the CurrentTemperature Relationship of Bare Overhead Conductors”, 1993.

[9] Working Group SC 22-12 Cigré (Chairman R. Stephen). "Probabilistic determination of conductor current ratings”, ELECTRA, No. 164, pp. 103-17, 1996.

[10] C.F. Price, R.R. Gibbon, "Statistical approach to thermal rating of overhead lines for power transmission and distribution", IEE Proceedings Pt C, Vol. 130, No. 5, pp. 245-56, 1983.

[11] F.R. McElvain, S.S. Mulnix, "Statistically determined static thermal ratings of overhead high voltage transmission lines in the Rocky Mountain region”, IEEE Transactions on Power Systems, Vol. 15, No. 2, pp. 899-902, 2000.

[12] B. Cauzillo, L. Paris, G. Pirovano, “Ampacity assessment of overhead line conductors as a compromise between safety and deregulated market requirements”, CIGRÉ Session, 22-206, Paris-France, 2002.

[13] R. Stephen, "Description of state of the art methods to determine thermal ratings of lines in real-time and their application in optimising power flow”, CIGRÉ Session, 22-304, Paris-France, 2000.

[14] F. Soto, D. Alvira, L. Martín, J. Latorre, J. Lumbreras, M. Wagensberg, "Increasing the capacity of overhead lines in the $400 \mathrm{kV}$ Spanish transmission network: real time thermal ratings”, CIGRÉ Session, 22211, Paris-France, 1998.

[15] S.D. Foss, S.H. Lin, H.R. Stillwell, R.A. Fernandes, "Dynamic thermal line ratings. Part II. Conductor temperature sensor and laboratory field test evaluation”, IEEE Transactions on Power Apparatus and Systems, Vol. 102, No. 6, pp. 1865-76, 1983.

[16] K. Adachi, T. Kumeda, K. Nagano, “A method for expanding the current capacity of overhead transmission lines”, CIGRÉ Session, V2-209, ParisFrance, 2004.

[17] T.O. Seppa, H.W. Adams, D.A. Douglass, N. Coad, A. Edris, P. Olivier, F.R. Thrash, "Use of on-line tension monitoring for real-time thermal ratings, ice loads and other environmental effects”, CIGRÉ Session, 22102, Paris-France, 1998.

[18] T.O. Seppa, S. Damsgaard-Mikelsen, M. Clements, R. Payne, N. Coad, "Application of real time thermal ratings for optimizing transmission line investment and operating decisions”, CIGRÉ Session, 22-301, ParisFrance, 2000.

[19] C. Mensah-Bonsu, G.T. Heydt, "Overhead transmission conductor sag: a novel measurement technique and the relation of sag to real time circuit ratings”, Electric Power Components and Systems, Vol. 31, pp. 61-69, 2003.

[20] R. Stephen, D. Muftic, "Determination of the thermal rating and uprating methods for existing lines”, CIGRÉ Session, 22-305, Paris-France, 2000.

[21] S. P. Hoffmann, A.M. Clark, "The approach to thermal uprating of transmission lines in the UK”, CIGRÉ Session, V2-317, Paris-France, 2004.

[22] A. Kikuchi, R. Morimoto, K. Mito, Y. Kimura, A. Mikumo, "Uprating of transmission capacity in 'Great Riyadh $132 \mathrm{KV}$ T/L grid system' by adopting small sag and thermal rate-up conductor”, CIGRE Symposium Leningrad, S 33-91, 100-06, 1991.

[23] M. J. Tunstall, S. P. Hoffmann, N. S. Derbyshire, M. J. Pyke, "Maximising the ratings of National Grid's existing transmission lines using high temperature low sag conductor”, CIGRÉ Session, 22-202, Paris-France, 2000.

[24] I. Zamora, A.J. Mazon, P. Eguia, R. Criado, C. Alonso, J. Iglesias, J.R. Saenz, "High-temperature conductors: a solution in the uprating of overhead transmission lines”, IEEE Power Tech, Porto-Portugal, 2001. 
[25] F.R. Thrash, "ACSS/TW - An improved conductor for upgrading existing lines or new construction”, IEEE PES Summer Meeting, pp. 182-85, 2001.

[26] R. Stephen, "Description and evaluation of options relating to uprating of overhead transmission lines”, CIGRÉ Session, V2-201, Paris-France, 2004.

\section{BIOGRAPHIES}

I. Albizu. He received his degree in Electrical, Electronic and Contro Engineering from the University of Navarra in 1998. He received his MSc degree in Electronic Instrumentation Systems from the University of Manchester Institute of Science and Technology (UMIST) in 1999. Currently he is $\mathrm{PhD}$ student in the Department of Electrical Engineering at the University of the Basque Country. His fields of interest include the Uprating of Overhead Lines and the Diagnosis of Induction Machines.

A. J. Mazón (M’03). He received his Electrical Engineering and PhD degrees from the University of the Basque Country in 1990 and 1994 respectively. During 1992 he worked in Labein Research Laboratories. He is currently Associate Professor in the Department of Electrical Engineering at the University of the Basque Country. His research activities include the Electric Power Systems, Transients Simulation, Fault Analysis and Uprating of Overhead Lines. He is IEEE member.

I. Zamora (M'03). She received her Electrical Engineering and $\mathrm{PhD}$ degrees from the University of the Basque Country in 1989 and 1993. Currently, she is Associate Professor and Head in the Department of Electrical Engineering at the University of the Basque Country. Her research activities include the Electric Power Systems, Transients Simulation, Fault Analysis and Uprating of Overhead Lines. She is member of CIGRE and IEEE. 